\title{
An Implementation of Different Non Linear PID Controllers on a Single Tank level Control using Matlab
}

\author{
D.V.L.N.Sastry \\ Assistant Professor \\ Department of EIE \\ AITAM, TEKKALI - \\ 532201
}

\author{
Gssssv.Krsihna \\ Mohan \\ Associtate Professor \\ Department of EIE \\ AITAM, TEKKALI
}

\author{
M.S.R.Naidu \\ Assitant Professor \\ Department of EIE \\ AITAM, TEKKALI.
}

\author{
N.Mohana Rao \\ Assistant Professor \\ Department of EIE \\ AITAM, TEKKALI.
}

\begin{abstract}
A Single tank level control system has one rectangular tank which has inflow of liquid into the tank and out flow through valve. The control System is intended to maintain the level of liquid in the tank at some predefined value irrespective of changes inflow of tank. Conventional PID controller gives better results due to changes in load. Thus change in inflow or changes in predefined values are treated as disturbances to the process. According to these disturbances we need to implement better tuning algorithms to PID controllers. But industrial conventional PID controllers exhibits nonlinear output for the given error values. Thus the approach of non linear PID controller is to include the disturbance parameters to conventional PID controller. The behavior is observed with step input. In this paper we implemented different non linear PID control algorithms on tank level control System and their responses are observed.
\end{abstract}

\section{Keywords}

Single Tank control, Non linear PID, MATLAB tool.

\section{INTRODUCTION}

A tank has the volumetric flow in is $F_{i}$ and out let volumetric flow rate is $F_{0}$.In the outlet stream there is a resistance to flow such as pipe,valve,or weir. The objective of control system is maintaining of constant height of tank irresptive of changes in inflow. The open loop transfer function of above tank system is given by [1]

$$
G(S)=\frac{K_{p}}{\tau_{p} S}
$$

Where $K_{p}=$ steady state gain of the process. And it is assumed to be 1 .

$\tau_{p}=$ Time constant of the process depends on area of tank.

Finally the transfer function is

$$
G(S)=\frac{1}{150 s}
$$

\section{NON-LINEAR PID ALGORITHMS:}

According to [2]., A non linear PID is one for which the principle of superposition does not apply.
The following are some of the non linear PID algorithms taken from [3] \& [4] and applied to the above tank level control system and their step responses are observed.

2.1 The Nonlinear PID (NPID) controller:

The NPID controller can be described as

$$
v=K_{\left[f\left(e, \alpha_{a, \delta_{a}}\right)+T_{. f\left(e, \alpha_{b}, \delta_{b}\right)}+T \quad f\left(e, \alpha_{c, \delta_{c}}\right) \mid\right.}
$$

where $\mathrm{e}, \int e$ and $e$ are the same as in the linear PID controller. $K P, T i$ and $T d$ are three parameterse linear PID controller. $f(*)$ is a nonlinear function .which is defined as

$$
\begin{aligned}
& \begin{array}{l}
f(x, \alpha, \delta)=\operatorname{singn}(\mathrm{m}) \cdot x^{\alpha} \\
\quad=\delta^{\alpha-1} \cdot \mathrm{m} \quad \text { when } \mathrm{m}>\delta \\
\mathrm{m}=\text { input } \mathrm{m}<\delta
\end{array} \\
& \alpha, \delta \text { are non linear parameters. }
\end{aligned}
$$

The response is shown in Fig:5

2.2 Error squared on Integral controller :

another nonlinear PID controller configuration developed to prevent integral or hysteresis plus

dead band cycling in level control loops. The Error Squared on Integral is implemented as follows:

$$
\mathrm{v}=K \quad\left(e+K_{i} \int \frac{e^{2}}{100} \mathrm{dt}\right)
$$

The response is shown in Fig:2

\subsection{Error square on PI controller:}

It is possible to create a controller with a continuous nonlinear function whose control action increases with error. This type of controller is called an error squared controller. The Error Squared controller is only used for PI control modes and not PID control: $\mathrm{v}=\mathrm{K} \quad\left(\right.$ e. $\left.\mathrm{e}+\mathrm{e}^{2} / 10000 \mathrm{~T}_{\mathrm{i}} \int \mathrm{edt}\right)$

2.4 Dead-band-reset algorithm:

Dead band Reset Scheduling (DRS) is the name given to an algorithm in which the controller integral setting is adjusted between a fast setting and a slow setting depending on the size of the control error (SP-PV).

$$
\begin{aligned}
& \mathrm{v}=\mathrm{k}_{\mathrm{p}}\left(\mathrm{e}+1 / \mathrm{T}_{\mathrm{i}} \mathrm{K}_{\mathrm{r}} \int\right. \text { edt } \\
& \text { if e }<\text { error gap then } K_{r}=5 \text { to } 15 \\
& \text { else } K_{r}=1
\end{aligned}
$$

The response is shown in Fig:3 


\subsection{Conditional integration solving over shoot} problems:

Batch processes are typically integrating type processes with a large lag time. The optimum control is a $\mathrm{P}+\mathrm{D}$ action controller without I. Any I action tuning, in a controller controlling an integrating process, will result in an overshoot following a set point change. In real processes,

integral action is required following load disturbances to integrate any small error to maintain the process variable at set point. The preferred controller algorithm is a PID controller with conditional integration. The conditional integration feature turns off the integral action when the error is large, and turns on the integral action when the error is sufficiently small.

$$
\begin{aligned}
& \mathrm{V}=K\left(e+K_{i} \int e d t+T_{d} \frac{d e}{d t}\right) \\
& \text { If } e \leq \frac{100}{K_{p}} \text { then } T_{i}=t_{d} \\
& \text { else } T_{i}=9999
\end{aligned}
$$

The response is shown in Fig:4

\section{SIMULATION RESULTS}

The controller parameters are selected by one of the tuning algorithms developed by Ziegler - Nicholos method and their values are

$$
K_{p}=0.007, K_{i}=0.00008, K_{d}=0.00003
$$

The following responses are obtained for above non linear algorithms.

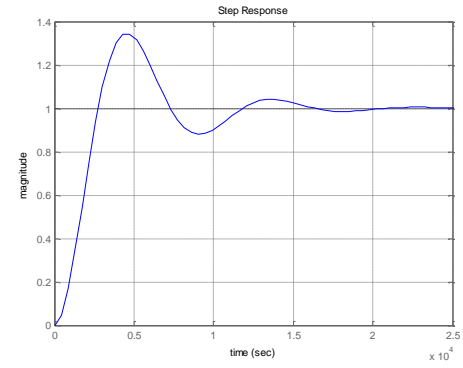

Fig:1 Response of linear PID

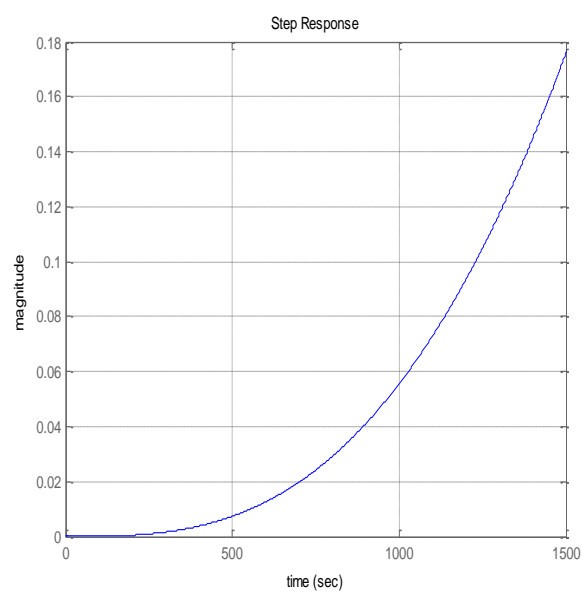

Fig:2 Response of error squared on I controller

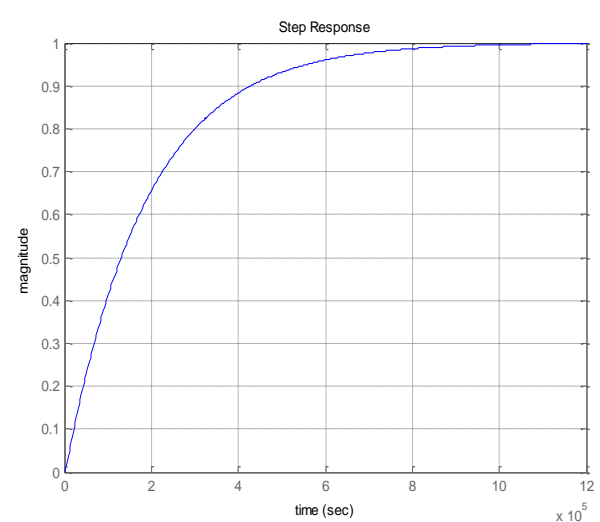

Fig:3 Response of DRS algorithm

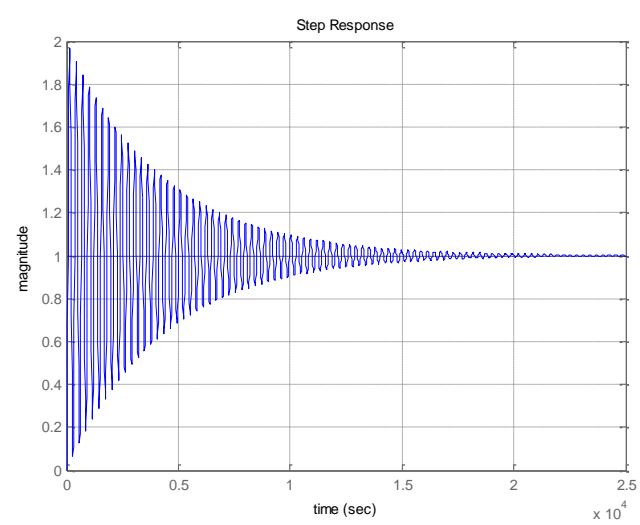

Fig:4 Response of conditional integration

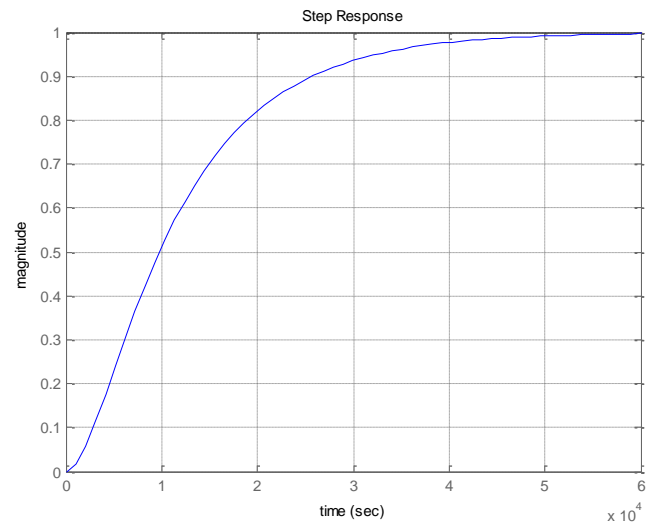

Fig:5 Response of NPID algorithm

The following table summarizes the step response characteristics of different non linear pid algorithms. 
Table: 1

\begin{tabular}{|c|c|c|c|c|c|}
\hline Parameter & $\begin{array}{c}\text { Linear } \\
\text { PID }\end{array}$ & $\begin{array}{c}\text { Error } \\
\text { square } \\
\text { on I } \\
\text { controlle } \\
\text { r }\end{array}$ & $\begin{array}{c}\text { DRS } \\
\text { algorith } \\
\mathbf{m}\end{array}$ & $\begin{array}{c}\text { Conditi } \\
\text { onal } \\
\text { integra } \\
\text { tion }\end{array}$ & $\begin{array}{c}\text { NPID } \\
\text { algori } \\
\text { thm }\end{array}$ \\
\hline $\begin{array}{c}\text { Peak } \\
\text { response } \\
(\%)\end{array}$ & 37 & -- & 0 & 100 & 0 \\
\hline $\begin{array}{c}\text { Settling } \\
\text { time (s) }\end{array}$ & 1.6 & --- & 7.2 & 1.7 & 4.2 \\
\hline $\begin{array}{c}\text { Rise time } \\
(\mathrm{s})\end{array}$ & 0.3 & --- & 7.2 & 0.01 & 4 \\
\hline $\begin{array}{c}\text { Delay time } \\
(\mathrm{s})\end{array}$ & 0.23 & $==-$ & 1.6 & 0.01 & 1 \\
\hline
\end{tabular}

\section{CONCLUSION}

The study of non-linear PID Controllers is an emerging field to get a mere understanding of implementation of linearization techniques. In this paper we studied and showed the simulation step response results of single tank level control system for different non linear PID algorithms. The conditional integration algorithm shows minimum rise time \& delay time compared to DRS algorithm shown in Table1.

This greatly improves the controller efficiency to maintain the level of water tank within the set point limit.

\section{REFERENCES}

[1] Chemical process control-An Introduction to theory and Practice by George Stephanopoulos, Pearson Prentice Hall - ISBN 81-7758-403-0.

[2] Process Systems Analysis and Control by Donald R.Coughanowr-Second edition -McGRAW-HILL International editions

[3] An Application of Nonlinear PID Control by Fangjun Jiang

[4] Special non linear PID controllers-www.protuner.com

[5] Non linear Digital PID controller by Shamim choudhury Texas Instruments .

[6] Process control instrumentation by - c.d.Jhonson

[7] Ziegler, J. G. and N. B., Nichols, "Optimal settings for automatic controllers", Trans. ASME, Vol. 64, pp. 759768 (1942).

[8] Cohen, G. H. and G. A., Coon, "Theoretical consideration of retarded control", Trans. ASME, Vol.75, pp. 827-834 (1953).

[9] Smith, C. A. and C. B., Corripio, Principals andPractices of Automatic Control, Wiley, New York,(1985). 